\title{
Elisions \& Illusions of Queerness: What Sacrifices Are Made in Appeals to a Mass Audience?
}

\section{Abstract}

This paper examines the impact of sacrificing queerness when adapting comics into films, which cater to wider audiences - specifically, queer elision in Ryan Coogler's Black Panther (2018) and illusions of queerness in Patty Jenkins' Wonder Woman (2017). The difference between elision and illusion is crucial, and so approached using different analytical modes. Black Panther's analysis is rooted in the production process, exploring how/why queerness is erased by drawing comparisons to the explicit queerness of Ta-Nehisi Coates and Roxanne Gay's comics. The analysis of Wonder Woman focuses on in-depth textual analysis of both Greg Rucka's comics and Jenkins's film to illustrate how queer illusions functions across media. Despite these films being hailed as progressive, this paper illuminates how motivations to hide queerness when moving to wider audiences are rooted in homophobia and protecting profit margins.

Keywords: queer, comics, comic-book movies, superheroes, Marvel, DC, Wonder Woman, Black Panther, film adaptations, homosexuality

Ramzi Fawaz's The New Mutants discusses comics as "a remarkable example of a queerly inflected, 'educated mode of desiring' in late 20th-century American culture," extensively outlining how superhero narratives "visually and affectively oriented readers toward an expanding array of queer figures, worldviews, and social relationships" (loc. 7999). I believe this emphatic claim, by juxtaposition, illuminates the lack of queerness (here used to, primarily, capture the wide array of nonconforming modes of attraction) in these stories' 21 st-century film adaptations ${ }^{[1]}$ To explore 
this, I will examine elisions and illusions of queerness in Marvel's Black Panther (2018) and DC's Wonder Woman (2017), alongside recent comic counterparts and their relevant popular cultural touchstones. These franchises require different analytical modes due to the nature of elision versus illusion: Black Panther's analysis is rooted in how/why production processes elide queerness, whereas Wonder Woman requires textual analysis to illustrate how queer illusions function, and why better representation is necessary.

Firstly, I must refer to Adorno and Horkheimer's foundational essay, which critiques mass media's homogeneity and its ability to distract audiences from reality. Adorno and Horkheimer claimed that the media function through false promises of wish-fulfillment, teaching consumers that "whatever the state of affairs, [they] must put up with what is offered" (38-39), calling the culture industry a corrupt "cathedral dedicated to elevated pleasure" (40). While these ideas have been critiqued at length, their claim that cultural executives do not "produce or sanction anything that ... differs from their own rules, their own ideas about consumers, or above all themselves" remains a valuable resource to draw from, as queer erasure is the byproduct of media homogeneity through capitalist policing of everything deemed outside of these "rules" in order to insure the highest profit margins (33).

With this grounding, I look toward Fawaz's ideas of enchantment to argue that "pleasure" has political power Adorno and Horkheimer are too quick to dismiss. Fawaz defines enchantment as "a constellation of emotions that might include wonder, exuberance, excitement, pleasure, and a host of ambivalent feelings that necessarily come with a 'surprising encounter' with the unknown, including fear, uneasiness, and confusion" (The New Mutants loc. 725). Fawaz responds to Adorno and Horkheimer, arguing this "might also just be called fun," "often disregarded as a minor entertainment effect of mass culture, or worse, an ideological ruse that blinds audiences to the underlying politics of the fantasies they consume" (loc. 734). Here, Fawaz unmasks Adorno and Horkheimer's elitism, instead advocating that popular culture can "[enchant] its potential audience by presenting a vision of a different world and offering encounters with figures of radical otherness that provide tools to subvert dominant systems" (locs. 749-756). However, if one believes, as Fawaz does, that comics can "[forge] a new ethics based on the dream of a world where difference and nonconformity might be valued as necessary components of social justice and collective well- 
being" (loc. 763), the question arises: what happens when people cannot even see themselves where they are deemed "necessary"?

In comic-to-film adaptation, necessary distillation is performed, as comics have "an indefinite unfolding," whereas "movies are a much more limited media in terms of time and space" (DeVega and Fawaz). Fawaz claims this results in films being more conservative than comics, whose "openendedness ... allows for such an expansive, progressive view of the world" (DeVega and Fawaz). As Marvel produces more movies, Fawaz feels this expansiveness is opening into films, citing the newer films' visual spectacle as reminiscent of comics, provoking enchantment which allows for movement towards more diverse casting etc. (DeVega and Fawaz). It follows this could allow for explicit queerness, but the Black Panther (BP) film still elides queerness completely, despite its explicit representation in BP's expansive comic series, primarily in Roxanne Gay's Black Panther: World of Wakanda (BP:WoW).

BP:WoW tells the Midnight Angels' (who feature throughout Ta-Nehisi Coates's Black Panther, the comics' mainline) origin-story and is simultaneously the love story of Ayo and Aneka, two female warriors sworn to serve Wakanda. Throughout BP:WoW and BP, there are panels of Ayo and Aneka acting as the norm for heterosexual couples in popular culture, kissing and discussing their relationship, and so queer readers need not "run against the grain ... of the most accessible voices ... in the texts themselves" (Sedgwick 4) to find queer representation. Particularly effective is Gay's portrayal of the beginning of their relationship in BP:WoW: on the surface, the pair flirt, while the reader is simultaneously privy to their thoughts through the use of varying "speech" bubbles (loc. 78). This interplay between internal/external embodies Fawaz's enchantment - both excitement and pleasure, and confusion within. This marks Gay's comics as a unique site for queer identification, mirroring Fawaz's discussion of comic characters' internal conflicts making space for reader's selfrecognition of emotions ${ }^{[2]}$

Additionally, BP:WoW does not fall victim to the performative liberalism Fawaz senses in newer comics, with characters such as "Muslim Ms. Marvel [and] a gay Batwoman" (Gay and Coates loc. 5748-5754). Fawaz argues these are instances of diversity being capitalized upon, or multicultural neoliberalism, and therefore do not contain the same enchantment. This harkens back to Adorno and Horkheimer's claims that culture standardizes difference, creating a "pseudo individuality" (40); 
while perhaps a valid critique overall, BP:WoW's queerness seems more complex, linking harmoniously with wider themes of the BP franchise (Coates and Lee). This is encapsulated by BP:WoW's love story working allegorically to explore loyalty to Wakanda and the king, culminating in Ayo and Aneka becoming the Midnight Angels and helping women in Wakanda (loc. 118-120). This illustrates "creative world-making practices," shaping "new kinds of political imaginaries," which is key to promoting progressiveness in comics, as it shows that "heterogeneity of [underrepresented] identities [can] and should change the world" (loc. 5770) - an idea Fawaz feels has been stripped from comics due to multicultural neoliberalism.

Gay (and co-author Yona Harvey) also mark the first Black women writing for Marvel - a definitive marker of progress - though, it must be noted Gay was hired because Coates was asked to recommend someone after BP's success (Serrao). Hence, this seems like a corporate decision made to capitalize on diversity, with higher-ups profiting significantly more than creators. Still, it is notable that Gay then "infiltrates" Marvel's homogenous space, using this platform not only to write more Black characters, but to write queer characters into BP's canon. This success was shortlived, with BP:WoW being cancelled in Marvel's "recent knock against 'diverse titles,"” with Marvel's VP reportedly having said they "'saw in sales'" that '"people didn't want any more diversity"' (Lachenal). The use of the word "more" here reveals deeper biases, showing that there is a perceived limit to the amount of diversity people will accept that feels "other" to them. This also aligns with Adorno and Horkheimer's idea that the culture industry produces homogenous content to avoid risking profit margins, while running in contradiction to how BP was marketed.

The BP:WoW series was cancelled days after BP's trailer premiered, despite the fact it could have helped gain audience traction (Lachenal). This is a counterintuitive choice to make in the lead-up to the film, especially when considering how central the comic book roots have been for the comic film genre. Liam Burke, in his book on Hollywood comic-book adaptations, discusses his audience research and finds that an idea of "fidelity" to comics is important to both fans and non-fans of the genre. Burke claims that "fans tend to view these films as adaptations and place a premium on the source, often using their online presence to safeguard fidelity," and while "non-fans" are more flexible in this regard, they still "value fidelity and are sensitive to online discussions [and] are wellversed in comic book movie conventions" (121-22). This idea of the fan "online presence" seems 
crucial, then, in discussing the choices made in both the lead-up to a film, as well as during the first weeks that the movie is showing in theaters. Burke frames this as "the 'power of fans' to create a box-office success" (Burke 155), based on whether or not movies are able to maintain their opening weekend box office the next weekend. If this does not occur, it is "normally a strong indicator that the film failed to cross over beyond its core fan base" (Burke 155).

When putting this strong emphasis on fans to create online intrigue leading up to the film's release and during its first weeks in theaters, the choice to cancel any BP related content appears nonsensical. I would argue this is symptomatic of filmmakers attempting to target specific voices they deem "important" for the film's success; with BP, Black voices were relied on to be the driving force across online media, to attract more Black filmgoers. This is evident when looking at how the marketing of BP was purposefully centered around Blackness - from the use of the iconic words of "The revolution will not be televised" by Gil Scott-Heron in the official trailer ("Marvel Studios' Black Panther - Official Trailer"), to the excitement built around starring Black actors and being directed by the first Black person in the Marvel Cinematic Universe (McCarthy). The use of Blackness here calls upon ideas established in bell hooks's introduction to Black Looks: Race and Representation, in which she asks, "From what political perspective do we [Black people] dream, look, create, and take action?" (hooks 4). hooks felt a need for radical, collective change in how culture represents Black people, and so she questioned which "types of images subvert, pose critical alternatives, and transform our worldviews and move us away from dualistic thinking about good and bad" (hooks 4). In doing so, she hoped "to create a world where everyone can look at blackness, and black people, with new eyes" (hooks 6). With news sources such as The New York Times claiming BP as "a defining moment for Black America" (Wallace), it seems that perhaps BP has begun to channel the new Blackness that hooks longed for then.

As such, the discussion around BP was centered around how incredible its Black representation was, and in advertising this way, Marvel engaged in a kind of cultural marketing that attempted to garner a different audience and bring them into the wider Marvel Cinematic Universe (as the characters would then be included in Avengers: Infinity War (2018)). Looking at the United States' audience demographics, we could conclude Marvel was successful $-37 \%$ of the audience was African-American in BP's first weekend sales, a substantially higher figure than the average 15\%. 
This is also interesting in relation to the number of Caucasian viewers, which shifted from its average of $52 \%$ to $35 \%$ (Horwitz). These demographics give us a sense of the power of representation and, as they show that Black people felt more inspired to see BP than other films, BP has become emblematic of the importance of being able to see oneself on the screen.

With these monumental demographic shifts, Marvel also proved that diversity can be marketable, but in specifically targeting a Black audience, its queerness was decidedly erased. I argue that this, in part, was due to Marvel not wanting to "risk" any more profits by mixing the message of "Blackness" with the subject of queerness. This reveals an underlying sentiment that they can only present so much "difference" to avoid alienating their "core market," which is seen as predominately white, heterosexual, and male (DeVega and Fawaz). This subsequently, unfortunately, promotes and perpetuates the erasure of intersections of race, sexuality, and gender, which is compounded by most queer narratives catering toward a white, gay male demographic $^{[3]}$ To include queerness in BP would be remarkable in terms of working against these societal weaknesses. In truth, this small subset's outcry that Marvel is catering to is not completely imagined. For example, a "group called 'Down With Disney's Treatment of Franchises and its Fanboys' were [sic] planning to tank [BP's] Rotten Tomatoes score," claiming to "have done the same with Star Wars: The Last Jedi [sic], due to its inclusion of new, diverse characters" (McCarthy). With movements such as these existing, eliding queerness in films like BP specifically panders toward this demographic to not further lose their grasp upon it, as, despite a shift occurring presently in the genre, they are still deemed important.

In addition, several months before BP:WoW's cancellation, Vanity Fair reported on early footage seen by journalists, describing a scene where, "Okoye [another female warrior] eyes Ayo flirtatiously for a long time as the camera pans in on them. Eventually, she says, appreciatively and appraisingly, 'You look good.' Ayo responds in kind. Okoye grins and replies, 'I know'” (Robinson). The article claimed this "lean[ed] into" the BP:WoW story's queerness; however, a "Marvel representative [said] the relationship ... is not a romantic one and that specific love storyline from [ BP:WoW] was not used as a source" (Robinson). This culminated in the scene not appearing in BP , and questions arose; when asked if there had been any intention of including a queer love story, 
BP's co-writer said "'the short answer [was] yes,"' but continued on to diminish his response, saying he was "'maybe having a brain fart"' (Whitney).

These suspicions were compounded when the film adaptation placed Okoye in a relationship with a man, W'Kabi (albeit a relationship with queer gender dynamics). Their relationship plays a significant role in the film's conclusion, relying on heteronormativity to lend it believability, as the pair's relationship is shaped around fleeting interactions only assumed romantic due to them being a heterosexual pairing. The main evidence of their relationship is that they use the descriptors "my love" or "beloved" for each other. On other occasions, there are moments where Okoye looks at W'Kabi in a serious manner, but there is little else to substantiate their relationship as husband and wife. It should be noted that this is barring a deleted scene released on the Blu-Ray and DVD editions, in which the couple discuss loyalty to T'Challa/Wakanda after Killmonger has been made King. As such, nationalistic ideas of loyalty were tied in direct relation to the couple and their hypothetical future children (echoing Ayo and Aneka in BP:WoW, where ideas of loyalty to one's country/king impact their relationship). This scene ends with the pair showing affection towards each other, which is otherwise exempt from the film's final cut ("Black Panther DELETED”). This deleted scene could potentially have added more weight to the film's conclusion, where W'Kabi ultimately surrenders to Okoye in battle. However, the fact that this concluding scene was still effective without any genuine interaction between the pair shows how heavily director Ryan Coogler could rely on the conventions of heteronormativity to explain this finale.

As stated previously, these different tensions of loyalty to a country and a relationship play out across both Okoye and W'Kabi's story and Ayo and Aneka's. However, it does not begin this way between Okoye and W'Kabi, as they first work harmoniously - as shown when Okoye addresses T'Challa and W'Kabi individually as "My king" and "My love" (BP). When viewing this in the light of the BP:WoW plot, where Aneka finds it difficult to reconcile loyalty to Ayo and T'Challa (loc. 39), this preserves the idea of the heterosexual coupling as unthreatening to one's loyalty to a country. Later, though, a similar dynamics is created once Eric Killmonger is made king and Okoye and W'Kabi's relationship begins to function allegorically and alongside the ideas of loyalty to one's love, one's king, and one's country. Here it must be noted that the formation of the Midnight Angels in $\mathrm{BP}: \mathrm{WoW}$ poses queer love as a "betrayal" of dedication to the king, in place of a deeper service 
to one's country, whereas "choosing" love in BP is posed as a unifying force on a national level. If Coogler had placed Okoye in a queer relationship, this could have posed queerness as a unifying force, a rarity in representing queer love. In doing so, BP could have truly proven that the genre has the propensity to shape "new kinds of political imaginaries," and demonstrate how "heterogeneity of [underrepresented] identities [can] and should change the world" (Fawaz, loc. 5770) ${ }^{[4]}$

Still, as it stands, the comic film genre remains too conservative to explore any of these possibilities. On the subject of queer elision in BP, Gay said, "Even when great progress is made, some marginalized groups are told to wait ... we're asking [for] too much, that we should be grateful for what progress is being made"' (Reynolds). This statement underscores how, although BP was heralded for its representation of Black people, it remained conservative as regards queerness. As such, BP echoes a sentiment present throughout society which places queer people as secondary, and, in doing so, BP inadvertently becomes a testament to the limits of performative liberalism.

To demonstrate the pervasiveness of this attitude and to argue for Gay's claims, I will briefly discuss Taika Waititi's Thor: Ragnarok (2017). Fawaz argues that the visual spectacle of films like Thor: Ragnarok is more reminiscent of comics, and that this element of the fantastical provokes enchantment, therein promoting diversity (DeVega and Fawaz). This is perhaps proven in part by casting Tessa Thompson as Valkyrie, who is originally depicted as white and blonde, whereas Thompson is a Woman of Color (McMillan). As such, one would believe that, if films were beginning to capture the more fantastical impossibilities of comics, perhaps queerness could also be made more explicit. In the case of Thor: Ragnarok, Thompson pushed for Valkyrie to be portrayed as bisexual, true to the comics. A scene was therefore shot of "a glimpse of a woman walking out of Valkyrie's bedroom," but this was "cut because it distracted from the scene's vital exposition" (Chitwood).

When discussing this choice, Waititi discusses openly that Valkyrie is bisexual, despite it not being explicitly displayed, and says that, "if you want to read anything into that you can make sense of it in parts of the film" (Chitwood). This is referring to a flashback scene where Valkyrie's warrior clan is killed, and Thompson has stated she acted as if Valkyrie was looking at her lover (Chitwood). On 
this scene, Waititi said, "perhaps ... that was her girlfriend. Who knows. We tried to make sure it wasn't super specific or that we were trying to say, 'She's a lesbian! She's bi! We really gotta get everyone on board with this!"' (Chitwood). This gesture to "reading into" a text will be further explored in reference to Jenkin's Wonder Woman film, because even if these cut scenes had been included in BP and Thor: Ragnarok, they would still ultimately have proved as illusory as the queerness in Wonder Woman, and at this point, one must ask: is the illusion of queerness enough anymore? Can queer people really continue to sustain themselves off of so little?

Though the few words of affection and the drawn-out looks between Okoye and W'Kabi establish their relationship as legitimate, this same privilege is not given to queer couples, as Wonder Woman's (WW's) long history of illusory queerness demonstrates. I trace this to D.A. Miller, who, in "Anal Rope" (on homosexuality in Hitchcock's Rope), discusses the harm in expressing queerness connotatively rather than denotatively (in keeping with Roland Barthes). Miller claims connotation “can't help appearing doubtful, debatable, possibly a mere effluvium of rumination ... fond of discovering in what must be read what need not be read into it" (118). As illustrated by Ayo and Aneka's internal rumination, "reading" situations and feeling uncertain are common queer experiences, but in moving to the denotative, BP:WoW reinstates and validates queer readings, whereas WW remains connotative. I argue this despite Greg Rucka, the current iteration's author, who has confirmed that Diana/Wonder Woman is queer ("Exclusive Interview"), which is sufficiently explicit to some (Jordan).

Miller considers connotative representation homophobic, because it helps "construct a homosexuality held definitionally in suspense on no less a question of its own existence [producing] homosexual subjects doubtful of the validity and even the reality of their desire, which may only be, does not necessarily mean, and all the rest." (119)

This highlights the true sacrifice made when keeping queerness illusory: it is felt most acutely by those unsure about their identities, as the connotative can instill and compound self-doubt in queer individuals, making it more difficult to feel a sense of certainty. Rucka's WW perpetuates this, because while "understand[ing] as best as [he] can the desire to see representation on the page," he feels this would be "bad writing" unless relevant to the plot ("Exclusive Interview"). He also undermines assurances of Diana's queerness by placing the onus on the reader, similar to Waititi 
with Valkyrie, when saying, "What matters is what you leave the book with. ... It doesn't matter [what] I say ... Can you find it? Is it there? Is it on the page ...? Then, there's your answer" (Rucka, "Exclusive Interview").

To demonstrate how Rucka "elide[s] [queerness] even as it is also being elaborated" (Miller 118), I point to a moment praised for being an explicit representation between Steve Trevor and Diana, who has left Themyscira to help the world of man:

Steve: Uh, was there... I mean, did you say good-bye to someone special?

Diana: I do not... special?

Steve: Someone... Important.

Diana: Kasia. Her name was Kasia. She said she understood but... It was not... Easy to say goodbye. ("Year One" loc. 95, emphasis added)

This heavily suggests Diana had a same-sex partner, but Steve's hesitancy in verbalizing this poses queerness as tolerated "only on condition that it be kept out of sight" (Miller 118). This is underscored because there is no "goodbye-scene" between Diana and Kasia on the page - a trope in heteronormative narratives when heroes leave. Rucka then overcompensates, spending three frames on Steve and Diana holding hands, therefore "[stimulating] what is considered, though insatiable, ... eventually ensur[ing] the proper formation of the romantic heterosexual couple" (Miller 128). Or, as Adorno and Horkheimer say: "pleasure is endlessly prolonged; the promise, which is actually all the spectacle consists of, is illusory" (38). Thus, Rucka performatively makes an effort to satiate queer readers (though perhaps infuriating some), stirring enchantment that disturbs the norm, but proves its illusory quality by reinstating heteronormative romance immediately.

Other queer moments prove even less substantial. For example, Diana's dynamics with Barbara Ann/Cheetah is akin to "lovers-turned-enemies" (Jordan), most aptly portrayed when they thrash violently together (Rucka, "The Lies" loc. 65), as "the choreography of their bodies relies prominently on Hollywood conventions of romantic embrace" (Miller 124). This imagery, also based in the "spectacle of gay sex," is repeated across other pages, as when Diana intimately comforts wounded, naked Barbara Ann. This homoerotic tension is supplanted by an illustration of Steve 
embracing Diana from behind, signaling the next chapter, which mimics Cheetah behind Diana on the issue's cover (Rucka, "The Lies" loc. 110-11; loc. 3).

Interestingly, Barbara Ann's queerness is said to be confirmed when she and another woman, Etta Candy, discuss the phrase "Suffering Sappho" (Rucka, "Year One" loc. 90) - part of "Wonder Woman lexicon" referring to Greek poet Sapphos, which became "a way to refer to [women who love women] without ... [narrowing] down their attraction" (Jordan). This instance of representation is undeniably a form of validation for queer readers, but it addresses them as separate from other readers, who may not read this moment as significant. It also requires a historical backing to understand, and as such, when given as evidence of queerness in WW, it illuminates its structural instability as "whoever would establish a given connotation can only support it through other connotations equally precarious" (Miller 119).

In shifting to a wider audience, Patty Jenkin's WW film makes queerness evermore illusory, following familiar conservative film conventions. In reviewing WW, Fawaz says, "If you really believed that [WW] would make lesbianism visible ... this may be the wrong film genre to invest in," claiming Diana as an object of enchantment and saying the opening scenes are "perhaps the most aggressive attempt by a superhero movie ever to give the left "what we want"' ("Notes"). This revolves around the enchantment of Themyscira, partially based on its existence as a homosocial space, as well as illusions of queerness. The existence of the homosocial space allows for many moments between Amazonian women to be read as queer, and the reasoning behind the frequency of these ideas is worth considering.

When discussing Diana's sexuality, both Rucka and the actress who plays her, Gal Gadot, have made references to how Diana's queerness "makes sense" because Themyscira is only populated by women (Lang). This validation of queerness as a sort of inevitability is also, to a lesser degree, present in BP:WoW, as both Aneka and Ayo are part of the all-female Dora Milaje. While there is some recognition of the illusory queerness that is present in homosocial spaces, it is vital to underscore that this queerness seems to exist by virtue of the absence of men. This, in itself, seems to operate and form a feedback loop of connotative queer meanings, where the opposite of queer validation can occur - since this queerness is not denotated, then "proof" of queerness in homosocial spaces proves insubstantial as being part and parcel of homosocial dynamics. This is 
what has begun to be referred to within queer communities jokingly as the idea of "gal pals," where queer relationships between women-assumed partners are "read" as simply close female friendship ("Gal Pals”).

The most notable example of this in WW occurs when Diana's aunt, General Antiope, is fatally wounded and her lieutenant Menalippe's reaction read romantically. Menalippe runs past the other Amazons, sounding anguished, and lingers longer than the rest, including Antiope's sister and niece. This behavior reads as "a transgression of the normally enforced boundaries between ... bodies" (Miller 124), mirrored by Diana holding Barbara Ann in the comics (and Aneka and Ayo's interactions in battles (Gay loc. 23-24)), and poses her as having lost her lover, later reinforced through her increased anger towards Steve. This example's tenuousness, as with all moments between Amazonians in Jenkins's film, proves Miller's point that discrediting connotated queerness is "as simple ... as uttering the words 'But isn't it just...?' before retorting denotation" (118).

It is also noteworthy that Diana herself is not central to these few queer moments in Jenkins's WW, unlike in Rucka's comics, where it is alluded to that she is potentially involved with multiple women ("Year One" loc. 13). Jenkins's film negates this possibility by placing all women in Themyscira as maternal figures for Diana: the audience's first experience of Themyscira is through Diana as a child, as she follows along with the Amazonians' training run by Antiope. Beginning in this manner, and by showing Diana growing up, Jenkins places Diana in a permanent state of adolescence within Themyscira. This is compounded by Diana not appearing to have any peers or friends, unlike Rucka's Diana, who exists as independent from her mother and aunt ("Year One" loc. 13). In this way, there is no space made for a hypothetical film-Kasia to exist, making it nearly impossible for Diana's queerness to be explored. The film only grants Diana independence from the women who shaped her once she leaves Themyscira, which coincides with moments shared with Steve Trevor, ridden with sexual undertones. By following this narrative, Jenkins lessens Diana's attachments to Themyscira, which then potentially allows her to better serve the "world of men." Taking this one step further, this also allows for Wonder Woman to better serve DC as a company - since she is not portrayed as having the same intense ties to her past that Rucka explores ("The Lies" loc. 6; loc. 151), her story and character is more malleable for use in other cross-over blockbusters, such as Justice League (2017). 
Interestingly, Fawaz argues enchantment remains throughout WW ("Notes”); I argue, as does queer theorist Jack Halberstam, that, after leaving Themyscira, there is a certain disengagement with the first act's enchantment (Halberstam). I trace this to the lack of the "bombastic" Fawaz calls for in films - the enchantment narrowing from the impossibility of the Amazonian island to the mundanity of war, a staple of many superhero films (DeVega and Fawaz). In addition, I propose a simplification of Halberstam's claim that Steve Trevor's "presence is intended to snuff out any fantasies of Amazonian love between women," to say Steve's purpose is "to snuff out [all] fantasies" (Halberstam). In this instance, "fantasies" can be applied in two forms - Fawaz's ideas of enchantment, as well as ideas of sexual fantasy, in the sense that the homosocial Themyscira's queerness can also cater toward ideas of the fetishization of queer women performed under the male gaze. This is exemplified when Diana and Steve discuss sex, Diana saying that "scholars" "came to the conclusion that men are essential for procreation, but when it comes to pleasure, unnecessary" (WW). This humorous remark, in the context of a man and woman discussing sex, manages to directly draw attention to the possibility of sex between Diana and Steve (despite attempts to subvert this), while negating illusions of queerness. The possible queerness here is easily erased, as when used as "proof," it can be refuted with, "But isn't it just about masturbation?" and thereafter, the story remains, generally, heteronormative (albeit queered in some gendered respects). This means the "target audience" remains unchallenged by queerness, so the film can be more widely distributed and consumed, leading, once again, to higher profit margins, while still allowing for queer readings. However, in their implicitness, moments in Themyscira become sites of multiple meanings which "can never be resolved" and "[keep] suspicion just that, a thing never substantiated" (Miller 118; 119).

It is also worth noting that Angela Robinson's biopic Professor Marston and the Wonder Women was released a few months after WW in 2017 (Robinson). The film, while highly fictionalized, made explicit the sexual elements of the polyamorous relationship between the original writer of the WW series, Professor Marston, his wife Elizabeth Marston, and their lover Olive Byrne. This relationship has not been widely discussed, to the point that it has the same illusory quality of homosexuality Miller critiques, even though their lives were not fictional (Berlatsky). The continuous denial and unrecognized potential that they were, in fact, queer, is in line with Sedgwick's arguments that the 
lack of "proof" of queerness (symptomatic of needing to hide homosexuality, historically) is used as evidence that "the author may be assumed to have been ardently and exclusively heterosexual" ( Epistemology 53). As such, through fictionalizing the Marstons' story, Robinson creates a queer narrative that asserts itself as truth, without allowing for any hint of the illusory quality of WW's queerness.

Interestingly, in marketing Professor Marston, reference was made to Jenkins's film through the tag line of "The year of Wonder Woman continues" despite the two films not being affiliated ("Professor Marston"). Considering that the two films exist in the same cultural epoch, there is an interesting tension created between the illusory queerness of WW and the explicit queerness of Professor Marston, which makes a point of drawing explicit links to the queer elements of the original WW comics, outlining ideas of bondage and submission being present. Clearly, as Professor Marston was Rated R in the United States, WW (rated PG-13) is intended for a very different target audience. However, WW drew in more viewers aged 50+ than an average superhero film, and so there is an increased possibility of overlapping audiences between the two films (even if these statistics primarily mark families with children) (McNary).

Though further research would be necessary to analyze the overlap of WW and Professor Marston audience members, it would be interesting to see how the varying depictions of queerness would influence views on each film. It is possible that viewers of both would feel they had more insight on Jenkins's WW and that it could have the effect of making the queerness more substantial - even for non-queer viewers. Viewing the two as companion texts, even if Warner Bros Pictures has not addressed Professor Marston as such, would cause a queer reading to occur more fluently, and some of the illusory qualities that Miller condemns could perhaps begin to be tackled through doing so, perhaps allowing room for a reparative reading of the text (Sedgwick, Touching Feeling 12353). However, as stated earlier, people uncertain of their identities are most vulnerable to connotative queerness, and often (though not always) this self-doubt is heightened amongst younger queer people. As such, the difference in age ratings between WW and Professor Marston makes this queer experience inaccessible for those who may need it most. Further, this kind of reading also places the onus on the reader and ultimately can only show that "through the imperfections of the joins, is the structure of the join itself, hence the very operation of the closet," 
by showing that the dissonance between these narratives is telling of a deeper homophobia (Miller 126).

It is vital to this discussion, however, to not negate the progress that has been made, and I would prefer to view the arguments made within this essay as a call to action and a way to illuminate how popular culture can be used to do more. The comics genre and its film counterparts have long been viewed as only of interest to a specific subset of people who tend to fit the mold of white, heterosexual, and cisgender men; Fawaz traces the history of this image becoming the prototypical consumer of comic books back to the industry's corporatization in the 1970s and 1980s, with comic books being relegated to comic-book stores and no longer existing within the public space and imagination (DeVega and Fawaz). This raised barriers and added a qualifier of necessary "knowledge about the space of the comic book store" that made becoming a comic-book fan more difficult. Fawaz claims that this possessiveness "is a fantasy" and says that despite this group feeling they have a claim over comics, "statistically ... they are not the only people reading those comics texts," even if the private space of the comic-book store has created that illusion (DeVega and Fawaz). In what acts as a response to the attempt to "tank" BP's Rotten Tomatoes rating, Fawaz feels that "sometimes the possessiveness doesn't come out of an actual ownership of those texts - it's out of a defensive fear that they don't own the texts, [and] that the texts are circulating in a wide range of people and now it's just becoming more and more visible" (DeVega and Fawaz).

This idea of visibility is key here - when comics are adapted into films, a wider audience experiences the world of the comics and can share within the fantasy and enchantment of these texts. The main positive outcome of adaptation, then, is that the genre becomes more public again, emulating a mode that is reminiscent of the fan letters that Fawaz discusses within Marvel comics, which he felt proved that "even if white boys were a preponderant number of readers ... they were by no means the only readers, or the people that were making the most meaning out of comics" (DeVega and Fawaz). This idea of making meaning from comics echoes the idea of queer readings, with Fawaz also claiming that when comics were at their peak, writers

wanted to project a kind of liberal, countercultural, progressive imaginary - they didn't want to go too radically to the left and alienate some of their conservative readers, but they also understood that the counterculture had started to recognize super heroes and comic books as this really 
radical space where you could reimagine the nature of what it means to be human... (DeVega and Fawaz)

This still rings true today, and it is precisely because of this balancing act that queerness is still being elided completely and left in the realm of the illusory. As discussed, the producers of BP created a "progressive imaginary" by depicting Blackness so boldly but still refrained from queerness to maintain this "balance." For WW, just as these comic writers included more radical letters within comics "to signal to their countercultural audience [as if saying] we are listening to you" (DeVega and Fawaz), queer illusions are operating to provide just the tiniest bit of sustenance, while remaining hidden. If the comic film genre is to truly embrace its potential to become this radical space, which would allow for people of all genders and sexualities to see themselves as being a part of this imaginative vision of "what it means to be human," then it must be pushed this extra inch further to truly make progress.

As for the audience that the corporate filmmakers view as essential, it seems that perhaps there is a "growing awareness that their opinions don't matter" (Nicholson). In the light of the success of films such as BP and WW, studios can see that "geek reactionaries comprise such an insignificant sliver of the potential box office that [they] can ignore their demands to go back to the early ComicCon days of submissive babes in bikinis" (Nicholson). To explore this possibility, I look toward the internet and social media as they are now, as they function similarly to how Fawaz discusses the letter pages as a crucial place for dialogue between people of varying backgrounds. This landscape is changing rapidly, perhaps most clearly portrayed in movements such as \#MeToo, which are being linked to the increase in female-directed films and more diversity (Nicholson). This highlights that perhaps something has significantly shifted since Burke's book was released rather than being able to rely on that "core" fan base to be the most present online voice and sway box office numbers, social media platforms are starting to lift voices previously marginalized up to the same level, or, perhaps optimistically, higher. It is highly promising to see the industry is beginning to hear these voices; Robinson describes this as "a slight lifting of the veil" where "a lot of executives and gate-keepers are looking around, like out of a haze, and saying: 'Wow, there's a lot of people out there who want different kinds of stories"' (Nicholson). 
Still, despite these steps forward, the industry continues to make moves to distill characters' queerness in films like BP and WW, to leave films more "purified" and unchallenging to the audience they have not fully stopped seeing as their target. This choice is only justified by placing financial gain over social conscience, and while one can claim that BP and WW are perhaps doing "enough," I feel this is limiting the potential of the genre. As it stands, both eliding queerness and illusions of queerness in these films, ultimately, have the same effect: a feeling of unease for queer viewers without the productive, political power of Fawaz's ideas of enchantment - instead, as Miller suggests, wishes remain unfulfilled.

When illusory promises are made to queer viewers, it seems Adorno and Horkheimer are in fact correct in saying that, "[t]o offer and to deprive them of something is one and the same" (39). In doing this, the culture industry perpetuates and fosters Gay's sentiment that society feels "we're asking too much, that we should be grateful for what progress is being made" (Reynolds). As has been demonstrated by the impact of representing Blackness and women in these films, to extend this genre's immensely powerful enchantment to include queer people could have profound implications in securing a sense of queerness as valid. Of course, this is not simple or straightforward, and this representation will require the same levels of nuance that Black Panther and Wonder Woman have granted Black people and women in order to create well-rounded queer characters. Still, one can only hope that, moving forward, both Black Panther and Wonder Woman film franchises, as well as other comic-book films, can be further emboldened to strive for the ideals which they portray and decide to use the power of popular culture for good.

\section{Works Cited}

Adorno, Theodor, and Max Horkheimer. "The Culture Industry: Enlightenment as Mass Deception." The Cultural Studies Reader, edited by Simon During, 2nd ed., Routledge, 1993, pp. 31-42.

Berlatsky, Noah. "The Crucial Thing the New Wonder Woman Movie Gets Right about the Character's History." The Verge, 16 Oct. 2017, https://www.theverge.com/2017/10/16/16481692/wonder-woman-professor-marston-homophobiahistory-sexuality-real-life-vs-fiction. Accessed 26 Aug. 2018. 
Black Panther. Directed by Ryan Coogler, Marvel Studios, 2018.

"Black Panther DELETED \& BONUS SCENES + Blu-ray Trailer." YouTube, uploaded by Flicks And The City Clips, 8 May 2018, https://www.youtube.com/watch?v=Ts8vqS_KEhM. Accessed 24 Aug. 2018.

Chitwood, Adam. "Taika Waititi Cut a 'Thor: Ragnarok' Scene That Made Valkyrie's Bisexuality Explicit." Collider, 1 Nov. 2017, http://collider.com/thor-ragnarok-valkyrie-bisexual-scene-cut-taikawaititi/. Accessed 16 Dec. 2018.

Coates, Ta-Nehisi, and Stan Lee. "Black Panther: A Nation under Our Feet." Black Panther, Kindle ed., book 1, Marvel, 2016.

DeVega, Chauncey, and Ramzi Fawaz. "Black Panther Special." The Chauncey DeVega Show, 16 Feb. 2018, http://www.chaunceydevega.com/2018/02/race-representation-and-blackdiaspora.html. Accessed 5 April 2018.

Fawaz, Ramzi. "Notes on Wonder Woman." Avidly, 16 July 2017, http://avidly.lareviewofbooks.org/2017/07/16/notes-on-wonder-woman/. Accessed 6 Apr. 2018.

Fawaz, Ramzi. The New Mutants: Superheroes and the Radical Imagination of American Comics. Kindle ed., New York University Press, 2016.

"Gal Pals." Know Your Meme, 2017, https://knowyourmeme.com/memes/gal-pals. Accessed 26 Aug. 2018.

Gay, Roxanne, Ta-Nehisi Coates, and Yona Harvey. "Dawn of the Midnight Angels.” Black Panther: World of Wakanda, Kindle ed., book 1, Marvel, 2017.

Halberstam, Jack. "'Suffering Sappho!' Wonder Woman and Feminism.” Bully Bloggers, 5 July 2017, https://bullybloggers.wordpress.com/2017/07/05/\%EF\%BB\%BFsuffering-sappho-wonderwoman-and-feminism-by-jack-halberstam/. Accessed 6 Apr. 2018.

hooks, bell. Black Looks: Race and Representation. South End Press, 1992.

Horwitz, Josh. “'Black Panther' Dramatically Changed the Make-up of the Superhero Movie Audience This Weekend." Quartz, 19 Feb. 2018, https://qz.com/1210475/black-pantherdramatically-changed-the-make-up-of-movie-audiences-this-weekend/. Accessed 25 Aug. 2018. 
Jordan. "Greg Rucka's Wonder Woman Is Beginning to Sift the Truth from the Lies." The Fandomentals, 16 Dec. 2016, https://www.thefandomentals.com/wonder-woman-truth-lies/. Accessed 3 Apr. 2018.

Lachenal, Jessica. "Roxanne Gay Confirms World of Wakanda's Disappointing Cancellation." The Mary Sue, 13 June 2017, https://www.themarysue.com/world-of-wakanda-cancelled/. Accessed 29 March 2018.

Lang, Brent. "Gal Gadot Dishes on the New ‘Wonder Woman’ Film.” Variety, 11 Oct. 2016, http://variety.com/2016/film/news/gal-gadot-wonder-woman-dc-patty-jenkins-1201884362/. Accessed 27 Aug. 2018.

"Marvel Studios' Black Panther - Official Trailer". YouTube, uploaded by Marvel Entertainment, 16 Oct. 2017, https://www.youtube.com/watch?v=xjDjIWPwcPU. Accessed 25 Aug. 2018. McCarthy, John. "How Marvel's Black Panther Marketing Campaign Married Movie and Movement". The Drum, 09 Feb. 2018, https://www.thedrum.com/news/2018/02/09/how-marvelsblack-panther-marketing-campaign-married-movie-and-movement. Accessed 25 Aug. 2018. McMillan, Graeme. "Valkyrie: The Comic History of Thor: Ragnarok's Breakout Star." Wired, 11 June 2017, https://www.wired.com/story/valkyrie-thor-ragnarok/. Accessed 3 Sept. 2018.

McNary, Dave. “'Wonder Woman': Female and Older Moviegoers Powered Box Office, New Study Shows." Variety, 6 July 2017, https://variety.com/2017/film/news/wonder-woman-study-box-office1202488262/. Accessed 26 Aug. 2018.

Miller, D.A. "Anal Rope." Representations, vol. 32, 1990, pp. 114-33. Jstor, doi: 10.2307/2928797. Nicholson, Amy. "Goddesses of the Galaxy: Women Directors Take over the Blockbuster Universe". The Guardian, 11 May 2018, https://www.theguardian.com/film/2018/may/11/goddesses-of-the-galaxy-women-directors-takeover-the-blockbuster-universe. Accessed 26 Aug. 2018.

Professor Marston and the Wonder Women. Directed by Angela Robinson, Annapurna Pictures, 2017. 
Professor Marston \& The Wonder Women. "The year of Wonder Woman continues...." Facebook, 21 Oct. 2017, 9:55 p.m.,

https://www.facebook.com/marstonmovie/photos/a.355529514871187/375973849493420/?type=1\&theater.

Accessed 27 Aug. 2018.

Reynolds, Daniel. “Don’t Forget Roxane Gay (and Queer Superheroes), Hollywood!” Advocate, 15 Feb. 2018, https://www.advocate.com/media/2018/2/15/dont-forget-roxane-gay-and-queersuperheroes-hollywood. Accessed 30 March 2018.

Robinson, Joanna. "Black Panther Footage Reveals the Ferocious Female Warriors of Wakanda [Updated]." Vanity Fair, 18 April 2017, https://www.vanityfair.com/hollywood/2017/04/blackpanther-gay-danai-gurira. Accessed 27 March 2018.

Rucka, Greg. “The Lies.” Wonder Woman, Kindle ed., vol. 1, DC Comics, 2017.

Rucka, Greg. "Year One.” Wonder Woman, Kindle ed., vol. 2, DC Comics, 2017.

Rucka, Greg. "Exclusive Interview: Greg Rucka on Queer Narrative and WONDER WOMAN," by Matt Santori. Comicosity, 28 Sep. 2016, http://www.comicosity.com/exclusive-interview-greg-ruckaon-queer-narrative-and-wonder-woman/. Accessed 31 March 2018.

Sedgwick, Eve Kosofsky. Epistemology of the Closet. University of California Press, 1990.

Sedgwick, Eve Kosofsky. Touching Feeling: Affect, Pedagogy, Performativity, Duke University Press, 2004.

Sedgwick, Eve Kosofsky. Tendencies. Routledge, 1993.

Serrao, Nivea. "Roxane Gay's 'World of Wakanda': How Scandal Inspired the New Marvel Comic." Entertainment Weekly, 2 Nov. 2016, http://ew.com/article/2016/11/02/roxane-gay-world-wakandamarvel/. Accessed 6 Apr. 2018.

Wallace, Carvell. “Why 'Black Panther' Is a Defining Moment for Black America.” The New York Times Magazine, 12 Feb. 2018, https://www.nytimes.com/2018/02/12/magazine/why-blackpanther-is-a-defining-moment-for-black-america.html. Accessed 13 Dec. 2018. 
Whitney, E. Oliver. “'Black Panther' Screenwriter Joe Robert Cole Addresses Rumors of a Deleted Gay Romance”. ScreenCrush, 12 Feb. 2018, http://screencrush.com/black-panther-gaycharacters-ayo-okoye-scene/. Accessed 27 March 2018.

Wonder Woman. Directed by Patty Jenkins, Warner Bros., 2017. 
[1] I invoke, here, the definition of queer by Sedgwick, as "the open mesh of possibilities, gaps, overlaps, dissonances and resonances, lapses and excesses of meaning when the constituent elements of anyone's gender, of anyone's sexuality aren't made (or can't be made) to signify monolithically" (Tendencies 8).

[2] Fawaz reflects on this extensively in Chapter Two, focusing on "The Fantastic Four" (loc. 14311978).

[3] See: "Will and Grace," "Glee," "Brokeback Mountain," "Modern Family," "Call Me by Your Name," etc.

[4] Arguably, this results in queer nationalism, but as nationalism is somewhat inherent to the comics genre, this is perhaps one of the few ways queerness could be deemed acceptable within these confines.

\section{(c) (i) $(9)$}

Creative Commons Attribution-NonCommercial-NoDerivatives 4.0 International License 